\title{
Plant characteristics determination in sand pits near Moscow
}

\author{
Alaa Dabbagh ${ }^{1, *}$ \\ ${ }^{1}$ Faculty of Ecology, PFUR, post-graduate student, Miklukho-Maklaya street 6, 117198, Moscow, \\ Russia.
}

\begin{abstract}
Sand pits are man-made landforms, where vegetation selfrestoration becomes very difficult. An in-depth study of sand pits' flora and vegetation must be done in order to restore the complete canopy on sand substrate, which prevents the movement of slopes. In Zvenigorod and Dzerzhinsk sand pits, aged about 70 years, we have studied the slopes with northern and southern exposure for 3 years. The article shows that all the 131 species which we have found in the surveyed area were species of vascular plants. Projective cover degree made up $20-30 \%$ which, in general, is a typical characteristic of sandy terrain. Hemicryptophytes dominate the spectrum of life forms by K. Raunkiaer in our research. According to the classification of life forms by I. G. Serebryakov, sand slopes are dominated by herbaceous perennial polycarpics, among which long and short rhizome plants and tap rooted plants are in majority. A significant proportion of tap rooted plants is due to their high degree of adaptation to strong light conditions and resistance to drought. Long- and short rhizome plants tend to loose substrates and soft soils.
\end{abstract}

\section{Introduction}

Sand, the main reserves of which are confined to the moraine-glacial deposits of the Quaternary period, is extracted by the open method. After the completion of the work, the sand pits must undergo reclamation: with mechanical profiling and subsequent revegetation, but in most cases the vegetation of the sand pits is left to self-repair [1]. For more rapid reclamation and the prospects for further use of disturbed lands, it is important to study the ecological features of plant communities' growth in sand pits.

The objective of this research is to examine ecological characteristics of sand pits vegetation (in two sand pits near Moscow). The results of our study can be used to plan the processes of stabilizing sandy slopes or reclamation of sand pits. The obtained data supplement the available data on the regularities of the formation of plant communities. Quarry studies are of great importance in terms of developing recommendations for the restoration of vegetation or the use of disturbed territories for economic purposes.

\section{Materials and methods}

\footnotetext{
Corresponding author: alaa_dabbagh@hotmail.com
} 
Materials for the work were collected in the summer of (2015, 2016, and 2017) during field research in two sand pits of Moscow region (Zvenigorod and Dzerzhinsky). For future comparison, the observations were made in each sand pit on the slopes of northern and southern exposure. To study species diversity geo-botanical description is carried out using the standard method in the area of $5 \times 5$ meters. Basic ecological and bio-morphological characteristics for each species of plant were settled. Life forms are defined by the system K. Raunkiaer and I.G Serebryakov [2.3]. Ecological characteristic assessment of habitats was carried out using G. Ellenberg ecological scales [4]. Ecological-cenotic groups were determined according to M.V. Kazakova [5]. Plant names are given by I.A. Gubanov [6].

\section{Results and Discussion}

\subsection{Species diversity of vegetation of sand pits}

Determination of the species diversity of vegetation in the study areas is fundamental for the formation of a strategy for restoring the vegetation cover on a sandy substrate: only by inventorying the species can one go on to selecting the range of plants for further work. In both sand pits (Zvenigorodsky and Dzerzhinsky) vegetation was rarefied. Only 131 species were found in the surveyed area of the sand pits during the three years of our research. Projective cover degree made up $20-30 \%$ which, in general, is a typical characteristic of sandy terrain [7]. In this case the number of species is not only determined by the smooth running development of the landscape (taking into account the fact that the interference was rude and had a man-made factors), but by other factors such as steep slopes, light, moisture, and richness of the soil.

\subsection{Spectrum of life forms of plants in sand pits according to K. Raunkiaer}

Hemicryptophytes are typical life form, prevailing in all plant communities of central Russia. In arid zones, terophyte should dominate according to K. Raunkiaer. (Fig.1).

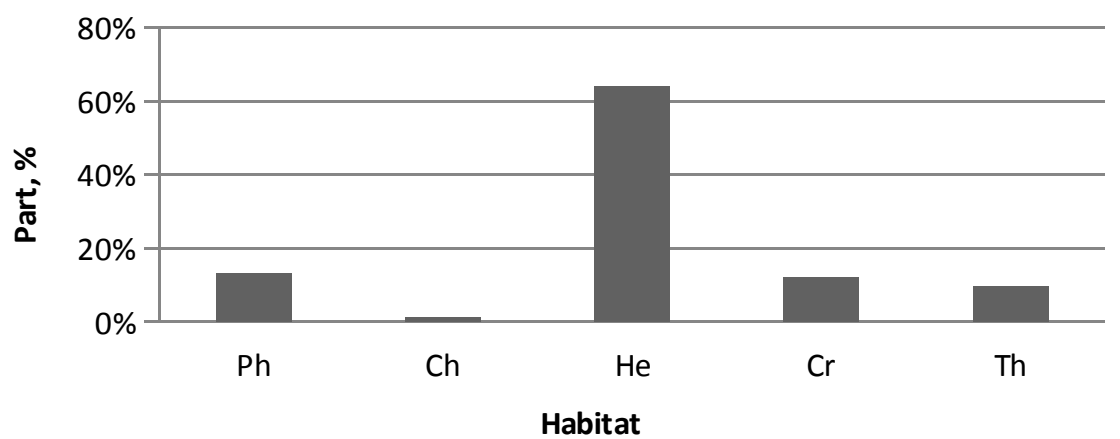

Fig. 1. Spectrum of life forms according to the system of K. Raunkiaer on different habitats. Notation keys: Ph-phanerophytes, Ch-chamaephytes, He-hemicryptophytes, Cr-Cryptophyte (geophytes), Ththerophytes

Hemicryptophytes dominate on the northern and the southern slopes of sand pits which is typical of central Russia vegetation. Compared to the desert regions terophytes low share can be noted. On the contrary, the ratio (the proportion) of geophytes is low compared to the moderate area. The predominance of hemicryptophytes may be noted on the northern slopes (with a set of environmental factors more zonal) compared to more hot and dry 
southern slopes, reflects the typical climatic conditions of the temperate zone and the originality of the substrate on which the plants grow. It may be noted that Chamaephyte with a low share. Such differences, most likely, are not associated with the exposure of the slopes but with the species diversity of vegetation that spontaneously develops in each sand pit.

\subsection{Spectrum of life forms of plants in sand pits according to IG Serebryakov}

I.G Serebryakov more elaborated and detailed, classification of life forms compared to those of K. Raunkiaer allows for detailed analysis of the environmental factors impact on plant community.

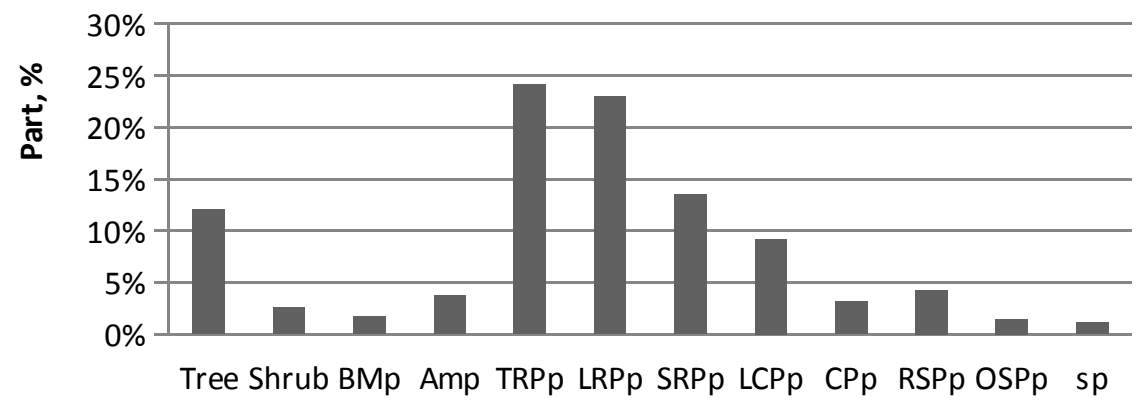

Life form

Fig.2. the spectrum of life forms by I. G. Serebryakov on different habitats. Notation keys: BMp biennial monocarpic; Amp - annual monocarpic; TRPp - tap root polycarpic; LRPp - long rhizome polycarpic; SRPp - short rhizome polycarpic; LCPp - loose cespitose polycarpic; CPp - creeping polycarpic; RSPp - root sucker polycarpic; OSPp - overground stoloniferous polycarpic ; $\mathrm{Sp}$ semishrub

According to life forms classification by I. G. Serebryakov (Fig. 2), sand slopes are dominated by herbaceous polycarpics, among which long- and short rhizome plants and tap rooted plants are in majority. A significant proportion of tap rooted plants is due to their high degree of adaptation to strong light conditions and resistance to drought [8]. Long- and short rhizome plants tend to loose substrates and soft soils, although the latter are more adaptive to the growing conditions. The presence of tap rooted plant due to their fitness to habitat high insolation and resistance to drought [9].

\section{Conclusions}

A study of the vegetation of the sand pits of the near Moscow region made it possible to identify and confirm the characteristic features of the formation of cenoses of these difficult habitats in ecological conditions. In particular:

1. The vegetative cover of sand pits is rarefied (in comparison with typical conditions of the humid taiga zone), the projective cover degree made up 20-30\%, which is typical for sandy landscapes.

2. In the spectrum of life forms according to K. Raunkier, hemicryptophytes predominate for sandy pits of the Moscow region, which is typical of central Russia vegetation

3. In the spectrum of life forms by I.G. Serebryakov for sand pits are dominated by herbaceous polycarpics, among them dominant are long- and short rhizome plants and tap rooted plants 
1. N.A. Berezina, N.B. Afanas'eva, Ekologija rastenij (Academa, Moscow, 2009)

2. AM. Aleynikova, EA. Vanisov, E.Yu. Vasilyeva, Izuchenie prerodnikh ikosystems (RUDN, Moscow, 2015)

3. Yu.E. Alekseev, P.Yu. Zhmylov, E.A. Karpukhina. Rastenya gorada Dubna (IUNSAM, Moscow, 2014)

4. P.Ju. Zhmyljov, A.P. Zhmyljova, E.A. Karpukhina, Opredelenie uslovij sredy po rastitel'nosti (Energija, Moscow, 2013)

5. M.V. Kazakova, Flora Rjazanskoj oblasti (Russkoe slovo, Rjazan, 2004)

6. I.A. Gubanov, K.V. Kiseleva, V.S. Novikov, V.N. Tihomirov. Opredelitel' sosudistyh rastenij centra evropejskoj Rossii (Argus, Moscow, 1995)

7. B.A. Bykov, Osnovnye ekobiomorfy pustynnyh rastenij Turanskoj nizmennosti (Kazakh Science. CCP., Almaty, 1987)

8. E.V. Abakumov, Pochvovedenie, E8, 955-963 (2008)

9. H.T. Gajrabekov, S.B. Macaev, M.V. Geroeva, Vestnik KrasGAU. E4, 128-133 (2012) 